\title{
El problema de las bandas en España como objeto de producción académica y de activismo etnográfico*
}

\author{
Luca Queirolo Palmas \\ Universidad de Génova \\ luca.palmas@unige.it
}

\section{Resumen}

En España, el asunto de las bandas es un objeto problema que, desde el año 2003, instituye y anticipa la producción de un discurso público sobre la juventud de origen migrante; un hecho social y una narrativa mediática que permite fijar el carácter peligroso de nuevos sujetos que circulan por el espacio urbano y vincularlos con una etnicidad supuestamente definitoria (las bandas latinas). ¿Cómo recibe la academia española este discurso de orden común constituido, en su mayor parte, desde los medios de comunicación? ¿Cómo se enmarca dentro de las perspectivas teóricas existentes? ¿Cómo actúan los académicos en el campo de las intervenciones que los poderes públicos realizaron a partir de 2004 para vigilar, castigar, corregir y transformar estas categorías de jóvenes? El artículo pretende contribuir a explorar la relación entre la producción de las bandas como objeto y problema social y los académicos en calidad de autores y actores. La base empírica del texto se sustenta en la realización de entrevistas en profundidad en Madrid y Barcelona a distintos grupos de interés institucionales y académicos, así como en la experiencia etnográfica en la escena callejera.

Palabras clave: juventud; migraciones; bandas; bandas juveniles; etnografía; sociología de la ciencia; política social

* Este artículo es parte de una investigación más amplia en el marco del proyecto de investigación europea YOUGANG (Gangs Policies: youth and migration in local contexts, www. yougang.udl.cat). La investigación ha sido financiada a través de una Marie Curie Intra European Fellowship ( $7^{\text {th }}$ European Community Framework Programme) en la Universidad de Lleida. La base empírica del texto se sustenta sobre un significativo esfuerzo de investigación empírica realizado entre octubre de 2011 y julio de 2013: 79 personas han sido entrevistadas y contactadas en Madrid y Barcelona entre los distintos actores que intervienen en la escena pandillera (policías, educadores, técnicos de juventud, líderes de las organizaciones callejeras, políticos, sacerdotes, jueces, profesionales de medios de comunicación y académicos), y sus relatos individuales han sido archivados bajo distintos formatos (audio, visual y notas de campo). La entrevista focalizada ha sido acompañada por una larga 
Abstract. The gang problem in Spain: An object of academic production and ethnographic activism

Since 2003, the topic of gangs in Spain has become both an object and a problem in the public discourse on migrant youth; a social phenomenon and a media narrative which establishes the dangerous nature of new social subjects in urban spaces and closely connects them with ethnic labelling (Latino gangs). How is this discourse received by Spanish academia and rearticulated in the existing theoretical frames? How do academics act in the field of policy interventions that have attempted to control, punish, correct and transform the gang experience as a form of youth sociability since 2004? This article explores the relationship between the gang as a problem-object in public discourse and policies and academics as authors and actors. The methodology is based on in-depth interviews with institutional and academic stakeholders in Madrid and Barcelona and on ethnographic experiences with street gangs.

Keywords: youth; migration; gangs; youth gangs; ethnography; sociology of science; social policy

\section{Sumario}

1. Estudiar y producir un objeto problema

2. Humanismo, patología, reproducción y resistencia

3. El objeto banda en la producción científica española
4. La acción etnográfica: entre autonomía y control político

5. Conclusiones: intelectuales orgánicos

y académicos embedded

Referencias bibliográficas

observación etnográfica, tanto con los jóvenes de las organizaciones callejeras como con los actores que intervienen sobre ellos. Además, 9 focus groups, realizados en Génova, Madrid y Barcelona, han implicado a 94 personas de distintas agencias institucionales encargadas del tratamiento del fenómeno. En los primeros 6 meses de 2013, un taller de producción visual ha involucrado a 20 jóvenes de los grupos callejeros en Barcelona. En fin, el sitio de Facebook de la película Buscando respeto nos ha permitido entrar en contacto con alrededor de 800 jóvenes de la escena pandillera en distintos países (especialmente en España, Italia, Ecuador, Santo Domingo y Estados Unidos). El autor ha podido observar en profundidad las relaciones entre los distintos actores institucionales. En 2012, formó parte de un taller de discusión alrededor del tema "Violencia y espacio público», es decir, las bandas según los relatos de los participantes, invitado por el Gabinete de Seguridad del Departamento de Interior de la Generalidad de Cataluña, en calidad de director del proyecto Yougang. Además, en noviembre de 2012, el Ayuntamiento de Barcelona me encarga asesorar el Servicio de Gestión de Conflictos de Ámbito Social en el Espacio Urbano, en la definición de unas líneas teóricas "para la intervención en el fenómeno de las bandas» y de acompañar la formación de un nuevo equipo de trabajadores sociales especializados en el tema. Aquí, nos concentramos sobre los actores académicos y las relaciones entre académicos y demás actores que aparecen en los relatos de entrevistas y en la observación etnográfica; 4 entrevistas focalizadas han sido realizadas con los grupos de investigación que, en Madrid y Barcelona, han llevado a cabo la investigación y la acción etnográfica con las bandas. En el presente texto, utilizamos la palabra banda, sabiendo que se trata de una categoría etic, difuminada por las agencias de control social y que no corresponde al lenguaje emic de los jóvenes miembros, que prefieren hablar de coro, grupo, nación, asociación, clica, familia y organización. 


\section{Estudiar y producir un objeto problema}

En España, el asunto de las bandas es un objeto problema que, desde 2003, instituye y anticipa la producción de un discurso público sobre la juventud de origen migrante. Se trata de un hecho y de una narrativa mediática que permiten fijar el carácter peligroso de nuevos sujetos que circulan por el espacio urbano y vincularlos con una etnicidad supuestamente definitoria (las bandas latinas). Sin embargo, la abundante literatura académica existente al final de los años noventa sobre las tribus urbanas no se apoderará de este objeto (Queirolo Palmas, 2012). Como señala García Borrego (2003), la partición dicotómica entre migrantes y no migrantes reverbera entre segunda generación, por una parte, y juventud en abstracto, por otra. Si la primera, por el lastre del origen, será estudiada a partir de su condición de foránea, la segunda recaerá legítimamente bajo el umbral de los estudios culturales de la juventud. Podemos profundizar en la partición propuesta por García Borrego considerando las bandas como el signo violento y colectivo que, en la mirada de la sociedad receptora, instituye la emergencia de una sociabilidad juvenil migrante; mientras que las tribus urbanas irán a constituir el campo de las sociabilidades posmodernas y de estilo de la juventud autóctona. Esta operación de visión y división permite construir una otredad juvenil donde proyectar confortablemente e imputar las causas de peligro, riesgo y violencia, en detrimento de la sociedad receptora. Además, en los últimos diez años y en términos de etnificación, las bandas, en el discurso común y en la opinión docta, serán latinas, con lo cual acompañan simbólicamente los grandes flujos migratorios que cambian la composición de la España inmigrante ${ }^{1}$.

¿Cómo se recibe en la academia española este discurso de orden común constituido en su mayor parte desde los medios de comunicación (Queirolo Palmas, 2013)? ¿Cómo se enmarca dentro de las perspectivas teóricas existentes? ¿Cómo actúan los académicos en el campo de las intervenciones que los poderes públicos realizaron a partir de 2004 en España, en la tentativa de vigilar, castigar, corregir y transformar estas categorías de jóvenes? El artículo pretende contribuir a explorar la relación entre la producción de las bandas como objeto problema social y los académicos en calidad de autores y actores. Por un lado, el texto

1. Hay que volver al fenómeno quinquis (Cuesta et al., 2009) para ubicar un uso anterior del término banda en el campo de lo juvenil. Desde la transición democrática en adelante, una juventud de clase popular, y en parte sesgada por lo gitano y la migración interna, construyó estéticas y prácticas delictivas de reapropiación de la riqueza. Estos sujetos — nombrados quinquis (de quincalla, ferretería, negocio al cual se dedicaban muchos gitanos) o quillos (de chiquillos, apelativo común en Andalucía) — abrieron un género narrativo y cinematográfico e impusieron unos protagonistas con sus gestas en las noticias de sucesos (El Vaquilla, El Torete, etc.). El objeto social banda es un dispositivo utilizado para designar las formas de socialidad inconformes de las clases peligrosas, en especial, de aquel segmento, a menudo étnico o etnificable, de las juventudes de origen proletario, es decir, los que, en la Revolución Industrial inglesa, eran pensados como undeserving poors y tratados a través de la Ley de trabajo y corrección y de prohibición del vagabundeo. En relación con la construcción contemporánea del objeto banda, los quinquis generaron una épica y una afirmación de protagonistas, una industria mediática claramente distinta a la que se implanta hoy sobre los jóvenes de origen migrante. 
pretende problematizar el discurso académico poniendo en evidencia la construcción y la producción de un objeto científico en la España contemporánea; por otro, mostrar a los académicos como actores que se posicionan y toman la palabra en un campo en donde se desarrollaron políticas de intervención desde las manos derecha e izquierda del Estado (Bourdieu, 2012). El objetivo del presente texto apunta tanto a deconstruir el naturalismo del discurso hegemónico sobre bandas y juventud callejera, como a cuestionar el papel neutral de la ciencia y a poner énfasis sobre las relaciones, cómplices y conflictivas al mismo tiempo, entre ciencia, política, administración y grupos subalternos —en este caso, las bandas - objeto de atención y tratamiento institucional.

\section{Humanismo, patología, reproducción y resistencia}

Podemos clasificar la literatura internacional sobre bandas siguiendo tres perspectivas, tal como plantea Brotherton (2010). La primera remite a los estudios clásicos de Thrasher (1963) y de White (1943) antes de la Segunda Guerra Mundial, en el marco de la Escuela de Chicago. Aquí, la banda hace parte de la ecología del barrio, se desarrolla en los procesos masivos de urbanización y migración, crece espontáneamente en los intersticios, sustentando alguna clase de respaldo moral allá donde hay desorganización, construyendo microsociedades juveniles entre pares que desafían material y culturalmente - a través de distintas formas de conflicto- el orden adulto. El conflicto es crucial y el crimen, una posibilidad, un evento, una contingencia que, sin embargo, no satura en ningún modo la vida ni la organización cotidiana del grupo. Dicho de otro modo, la banda es una formación cultural dinámica en un contexto de exclusión y de transformación social, que puede evolucionar hacia formas más asociativas, culturales y/o deportivas, así como especializarse en alguna clase de crimen. Como señala Kazyrytski (2008), en la visión de Thrasher, esta dinámica podía ir acompañada de intervenciones — sociales y políticasorientadas a la transformación de los grupos. Vemos aquí el espíritu humanista de la Escuela de Chicago, su atención a la importancia de la reforma social y su interés en profundizar la mirada sobre las significaciones que los actores construyen alrededor de sus productos culturales.

En la década de 1970, en Los Ángeles, Klein desarrolla una nueva definición que sigue siendo entre las más utilizadas hasta hoy, además de ponerse en sintonía con el discurso público no académico sobre el tema.

Una banda es un grupo de jóvenes que se puede identificar por: $a$ ) ser percibido como una agregación distinta de las demás en el barrio, $b$ ) reconocerse como un grupo definido, $c$ ) estar involucrado en varios episodios delincuenciales que generan una constante reacción negativa de los vecinos y/o de los servicios encargados de la aplicación de la ley. (Klein, 1971: 13)

Lo que evidencia esta definición es el criterio del crimen como marcador del grupo, más allá de toda la parafernalia de los signos, colores, nombres, juegos cruzados de autopercepciones y heteropercepciones. Banda es un agregado 
de jóvenes que conlleva y produce, entre los ciudadanos honestos, crimen, violencia y peligro, y esto genera una reacción social por parte de quienes tienen el mandato de proteger a la comunidad. Es esta una definición, en el origen de una visión más amplia, que Brotherton (2010) define como la mirada patologizante hacia las bandas: causas de enfermedades, monstruos urbanos que exigen ser tratados por las agencias de control antes que dañen y corrompan a la sociedad. Esta visión conlleva y habilita también toda clase de discursos y prácticas de signo correccional, de prevención y supresión. El crimen está pensado aquí como un objeto neutro, de infracción de un código penal o moral, que solo interroga marginalmente a las desigualdades sociales y a los vínculos que los individuos de distintas clases experimentan en el acceso a los recursos, y tampoco se vincula con los dispositivos de producción de imaginarios que constituyen las vidas y los deseos de las clases subalternas ${ }^{2}$. La violencia es, por ende, en el enfoque patologizante, una cualidad de las conductas de bandas y permite pensarlas como aglomeración de individuos desviados y asociales, más que como reproductores en otra escala de las mismas dinámicas de violencia operantes desde otras agencias sociales (la escuela, la familia, la policía, el ejército), creadores de otros alfabetos culturales de designación del mundo y/o transgresores conscientes del orden instituido. Además, esta fijación sobre la violencia, protagonizada por los jóvenes en bandas, oculta las violencias estructurales que los mismos padecen, invisibilizando lo que Bourdieu (1998) ha llamado "circularidad y conservación de la violencia».

Estos enfoques patologizantes han construido un consenso en la criminología y han cristalizado alrededor de la siguiente definición de banda callejera (Kazyrytski, 2008: 52) promovida por Eurogang3:

[...] un grupo juvenil, duradero, con orientación hacia la calle y otros espacios públicos y con una identidad grupal definida de forma primordial por la participación en actividades delictivas.

Esta red apunta a organizar conocimiento, comparaciones a través de protocolos de encuesta y definiciones compartidas, además de proporcionar soluciones y asesorar políticas y modelos policiales. De ella, forman parte, en cada país, un complejo interesante, y poderoso, de sujetos que une y hace cómplices a académicos, fuerzas policiales y otras instancias de la mano derecha del Estado ${ }^{4}$.

2. Como, por ejemplo, ya había hecho Merton (1980) en su clásica teoría de la desviación social y que, en las teorías norteamericanas de bandas, ha sido recogido por Cohen (1955) y Cloward y Ohlin (1966) sobre subculturas delictivas y estructuras diferenciales de oportunidades. Young $(1999,2007)$ propone utilizar el concepto de bulimia social, la contradicción entre la inclusión cultural y la exclusión material.

3. Una red de investigadores norteamericanos y europeos, liderada e inspirada, entre otros, por el mismo Klein (http://www.umsl.edu/ccj/eurogang/euroganghome.html).

4. La mayoría de mis informantes y entrevistados conocen Eurogang, se refieren a aquellas definiciones, reciben información electrónica proporcionada por Eurogang y han participado en algún seminario o conferencia. Se trata, en términos gramscianos, de un trabajo de hegemonía en las narraciones e intervenciones. 
La tercera perspectiva, de signo crítico, quiere enfatizar la capacidad creativa y de agencia de los subalternos, sus producciones culturales y sus formas de sociabilidad como prácticas de resistencia, por supuesto contradictoria y ambigua, frente a un conjunto de procesos de discriminación por cultura, raza, clase. En este sentido, Brotherton y Barrios proponen abandonar el término banda, estructuralmente sesgado por el crimen como cualidad intrínseca de los grupos, para sustituirlo por el de organización de la calle:

[...] grupos formados, en gran parte, por jóvenes y adultos provenientes de las clases marginalizadas, que tienen como objetivo proveer a sus miembros de una identidad de resistencia, de una oportunidad de empoderamiento tanto a nivel individual como colectivo, de una posible «voz» capaz de desafiar a la cultura dominante, de un refugio respecto de las tensiones y los sufrimientos de la vida cotidiana en el gueto y, finalmente, de un enclave espiritual en el que puedan desarrollarse prácticas y rituales considerados sagrados. (Brotherton y Barrios, 2004: 23)

En este enfoque, el crimen es una posibilidad además de un recurso cultural a través del cual se construyen nuevas elites de la calle (Katz, 1988). La violencia, más que un hecho fijo, se vuelve un sistema de comunicación y de civilización ${ }^{5}$ y, lo que en la mirada patologizante aparece como primitivo, se transforma en un lenguaje específico, un sistema literario propio de las clases subalternas, lo que Conquergood (1997) llama street literacy.

Mis investigaciones previas sobre la escena pandillera se sitúan claramente en este último tipo de acercamiento (Queirolo Palmas, 2009, 2010) y han permitido entender, en contextos de gran vulnerabilidad social y existencial, el desarrollo de algunos mecanismos cruciales de agencia por parte de los hijos de las migraciones: la transformación de la doble ausencia en doble presencia, la apropiación y resignificación de los espacios urbanos (home making), la transición de la condición de no-persona a la de hiperpersona a través del juego de los excesos y de una estética espectacular, la creación de códigos y lenguajes secretos con el fin de inmunizarse de las miradas hostiles, en definitiva, la transformación del estigma en emblema. Estas formas de creatividad social pasan a través de prácticas de re-naming (Brotherton y Barrios, 2004), procesos narrativos capaces de resignificar el mundo social, empezando por las necesidades del grupo y construyendo un nosotros que tenga y pretenda respeto. Las bandas serían, así, siguiendo la gramática de la sociología de Bourdieu, un vector de acumulación y circulación de distintos capitales (simbólico, social, cultural, económico) por parte de sectores desposeídos de la juventud.

5. Así como el boxeo y otros deportes, también las bandas constituirían una forma de civilización de la violencia, es decir, la construcción de normas de actuación y de reglas previsibles ante la posibilidad siempre presente del enfrentamiento entre grupos e individuos en la calle (Marengo, 2012). 


\section{El objeto banda en la producción científica española}

En relación con este mapa, ¿cómo se sitúa la literatura científica existente en España? Empezamos con algunas observaciones generales:

1) La producción académica especializada es escasa, reciente y asentada en algunas disciplinas (antropología, psicología social, sociología, criminología). Falta una literatura vinculada a políticas y a tratamiento de bandas, así como a la evaluación de las mismas.

2) El discurso académico más citado se sitúa en el marco de un enfoque crítico, aún si en las investigaciones sobre la juventud migrante quedan rasgos importantes de la visión que hemos llamado "patologizante». Sin embargo, la doxa patologizante sobre bandas en sociología, psicología y criminología se refleja fácilmente en el derecho y corrobora la producción de leyes y definiciones normativas.

3) Las etnografías realizadas han utilizado como caso de análisis un grupo específico (Reyes y Reinas Latinas), mientras faltan trabajos de investigación sobre las otras denominaciones callejeras, que solo han sido evocadas por el sensacionalismo de la prensa o como efecto de grandes dispositivos policiales.

4) Algunas investigaciones empíricas se sustentan únicamente en fuentes policiales o institucionales.

5) El papel de los académicos críticos ha sido también de intervención y relación con los grupos.

Confrontamos, por ejemplo, estas dos citas: la primera es de un sociólogo —entre los pioneros de los estudios migratorios en España y que, además, desempeñó la función de presidente bajo el gobierno socialista de una importante agencia estatal especializada ${ }^{6}$ - y aparece en el marco de una contribución más amplia sobre juventud y migración; la segunda proviene de un criminólogo y está fijada en un manual de derecho penal juvenil:

[...] la aparición de algunos fenómenos de bandas juveniles que importan prácticas asociativas y de cohesión de grupo de las bandas implantadas con anterioridad en sus países de origen, puede generar problemas de convivencia que deben ser combatidos antes de que logren instalarse entre nosotros, y se deben adoptar medidas preventivas que atajen las causas de las mismas. (Cachón, 2007: 61)

Se puede entender por banda juvenil un grupo de jóvenes unidos de forma permanente por mutuos intereses con las siguientes características: un nombre y una simbología que haga reconocible a la banda, un líder identificable, un territorio geográfico bajo su control, un lugar de reunión regular y una implicación en actividades delictivas. (Vázquez y Serrano, 2007: 41, 42)

6. Foro para la integración social de los migrantes, ubicado en la Secretaría General de Inmigración y Emigración (http://extranjeros.empleo.gob.es/es/ForoIntegracion/). 
La peligrosidad, la corrosión de los buenos valores nativos, así como la apropiación ilegítima de recursos ciudadanos, también aparecen en un reciente informe de la Fundación Santa María sobre juventud en España, que, en términos de definición, es tajante y apocalíptica, puesto que casi llega a comparar estas agregaciones juveniles con los grandes grupos mafiosos:

Las bandas juveniles de inmigrantes latinos no son simples pandillas, sino grandes organizaciones delictivas internacionales. (Juan González-Anleo Sánchez et al., 2010: 330)

Los autores imparten y explotan un cuestionario donde se pide a los encuestados si conocen y tienen amistades con las distintas bandas y qué nivel de simpatía expresan. El fenómeno resultaría, así, muy conocido, pero, al mismo tiempo, «muy minoritario y antipático para la inmensa mayoría de los jóvenes migrantes». Además, España, según dicho informe, se ha convertido en un «foco de atracción para las bandas latinas» (ibídem: 332) por sus ventajas sociales, entre otras: la gratuidad del sistema sanitario y educativo. Los jóvenes entrarían en las bandas o en las drogas por frustración y por un afán de poder, de control sobre el territorio y sobre las chicas (ibídem: 332). Se trata, por una parte y según estos analistas, de punir, rehabilitar y resocializar al infractor $y$, por otra, de responsabilizar a padres y escuelas, puesto que el problema de fondo no es estructural, no tiene que ver con procesos de integración subalterna y de resistencia, más bien es educativo, evoca la falta de valores y una ausencia de cuidado entre el entorno de socialización de los jóvenes de origen migrante.

El objeto problema banda entra también en las más recientes encuestas de Aparicio y Portes sobre las segundas generaciones en Madrid y Barcelona, trabajos en los que la palabra racismo no parece cobrar ningún papel. Por otro lado, se certifica, estadistica y cientificamente, la ausencia de una percepción de discriminación por parte de los entrevistados ${ }^{7}$. Aquí banda se transforma en una variable independiente capaz de explicar el fracaso escolar y el deterioro de las relaciones y de los centros educativos.

[...] los entrevistados confirman [...] la opinión general sobre el deterioro educacional asociado con las bandas y riñas entre grupos de distinta raza y etnia. Vemos aquí claramente dibujado el desafío que enfrenta el sistema escolar en neutralizar estos peligros, evitando o reduciendo la tendencia hacia la "asimilación descendente» —asociada con la participación en bandas y el abandono escolar- entre hijos de inmigrantes. (Portes et al., 2009: $28,29)$

7. Si, en esta investigación, la discriminación aparece como un hecho menor, a partir de las declaraciones de autopercepción de adolescentes entre 13,5 y 14,4 años (la edad media de la muestra en Barcelona y Madrid, respectivamente), contrariamente, para Iñaki García Borrego (2010), la discriminación es el acto mismo que construye, como grupo y como objeto, a los hijos de la migración. 
Los autores no se preguntan si el signo causal podría, por ejemplo, ser invertido, explicando las bandas como espacio de internalización, es decir, de integración de sujetos que fueron externalizados por prácticas educativas discriminatorias. Las instituciones son absueltas por la ciencia, mientras que las bandas tendrán que ser suprimidas y prevenidas, por ser sujetos responsables del deterioro escolar y social. La misma autora, Rosa Aparicio, conjuntamente con Andrés Tornos, publica, en 2009, una investigación realizada por encargo del Ministerio de Trabajo e Inmigración algunos años antes. Este texto asume acríticamente el término banda latina como territorio de la investigación, no accede a la voz de los grupos como fuente de información e interpretación alternativa, se limita a una teoría del déficit para explicar el sentido de la participación juvenil, desclasa los trabajos de la escuela crítica como obras apologéticas 8 y, en fin, menciona, pero no discute, la experiencia que las instituciones en Barcelona llevan adelante desde 2005, promoviendo cierta clase de reconocimiento de estos grupos y su transformación en asociaciones formalizadas. El diagnóstico será que el racismo es, sobre todo, una percepción y «ahí estaría, más que en los hechos, la humillación latina contra la que se levantan las bandas» (Aparicio et al., 2009: 93). Desde esta perspectiva, las bandas no resisten a la discriminación que lamentan padecer, sino que más bien la reproducen y generan prácticas contraproducentes para los fines declarados. La ostentación del poder y la posibilidad de ejercer y obtener una defensa poderosa (Aparicio et al., 2009) marcan, y limitan, el sentido y las prácticas de estos grupos callejeros.

Otros autores, desde la psicología social, también han fijado en la violencia juvenil el signo constitutivo de estos grupos. Como nos enseñan María Jesús Martín y sus colaboradores (2009), una teoría de la socialización nos puede ayudar a entender el fenómeno: por una parte, "la pertenencia a un grupo violento contribuye fuertemente a definir la identidad social en sus jóvenes integrantes», por otra, «es posible postular una sobre-socialización del grupo violento y una infra-socialización del resto de agentes socializadores», con el fin de explicar las conductas individuales (Martín et al., 2009: 133-134). El objeto banda juvenil violenta abarcaría aquí desde los latinos hasta los nazis, desde los anarquistas hasta los seguidores ultra de los equipos de fútbol, en un perfecto paralelismo con las definiciones policiales que, a partir del Plan de actuación y coordinación policial contra grupos organizados y violentos ${ }^{9}$, han comenzado a unificar bandas latinas y bandas antisistema en un mismo espacio de captura y tratamiento.

Todos estos textos se sitúan de alguna manera en la que hemos llamado «visión patológica de las bandas». No hay bandas sin violencia y crimen. Es también el enfoque que se impulsa desde la red Eurogang, que pretende, con

8. Se refiere al trabajo seminal de Barrios y Brotherton (2004) sobre Latin Kings, que reclasifica las bandas como movimientos sociales y de resistencia.

9. Promovido por el Ministerio de Interior y la Secretaría de Estado de Seguridad en 2005 y renovado en 2009. 
cierto éxito, desarrollar una floreciente gang industry en Europa. Estos relatos, aún más cuando son reforzados por una objetividad prometida a golpe de números y modelos cuantitativos o en virtud, simplemente, del capital políticoacadémico del locutor, generan consecuencias importantes en la producción del derecho. Como señala Maqueda Abreu (2010) en su recorrido por la criminología sobre el tema, estos saberes son fuentes inspiradoras de la política criminal contemporánea, del recrudecimiento de la ley del menor y de la acción penal sobre los jóvenes, conjuntamente con las clasificaciones y narraciones de otros productores de discursos expertos legitimados por el Estado (Fiscalía del Estado, informes judiciales y policiales y comisiones de investigación).

Paralelamente a estos trabajos, el campo académico está poblado y disputado por otra generación de investigadores, cuyas obras, en su mayor parte, se forjan en procesos de intervención social alrededor del fenómeno en Madrid y Barcelona (Feixa, 1998; Feixa et al., 2006; Scandroglio, 2009; Canelles, 2008; Scandroglio y López, 2010; Porzio y Giliberti, 2009; Giliberti, 2010; Romaní et al., 2009; Cerbino, 2011). En un caso (Barcelona), los investigadores gozan, en la etapa inicial (2005-2006), de un encargo institucional alrededor de la política de transformación de las bandas en asociaciones y, sucesivamente, de líneas de financiación vinculadas al tema más general de la juventud migrante y del uso del espacio público. En el otro (Madrid), el impulso del mismo proceso es dirigido de modo autónomo por los académicos y claramente obstaculizado por las instituciones ${ }^{10}$.

Los elementos que resaltan en estos estudios cuestionan profundamente la visión ontológica de la violencia juvenil, la teoría del déficit como marco explicativo, la fijación étnica de lo latino, el criterio de la distancia como apriorismo de la cientificidad de un discurso. Se trata, al revés, de pensar el contexto de múltiples violencias desde donde cobra sentido el acto individual (Porzio y Giliberti, 2009) y la economía simbólica del acto violento (Cerbino, 2011), de asumir las pertenencias como juegos y apuestas que conllevan ganancias, de imaginar lo latino como producto de una etnogénesis (Feixa et al., 2006) y las bandas como síntoma, espejo que «expresa mucho de quien emite esta calificación» (Canelles, 2008: 96), de situar en el mismo grupo callejero el marco de la etnografía y de la investigación-acción (Scandroglio y López, 2010).

Los resultados de estos trabajos sugieren, por un lado, mirar a las bandas como productos socialmente construidos desde múltiples instancias y con múltiples funciones, por otro, reconectar el análisis del fenómeno en el abanico de las culturas juveniles, rompiendo en cierto modo la partición entre autóctonos e hijos de migrantes, así como sus consecuencias a la hora de clasificar las formas legítimas e ilegítimas de sociabilidad de las juventudes. Las investigaciones llevadas a cabo presentan distintas valoraciones del carácter reproductivo (los

10. Asumimos los directores de los dos equipos - Carles Feixa y Oriol Romaní, en Barcelona, y Barbara Scandroglio y Jorge López, en Madrid- como actores del campo cuyos relatos y prácticas hemos archivado a lo largo de esta investigación, con el fin de representar el punto de vista académico en el análisis. 
grupos como reflejo de las relaciones de dominación en el orden social) o resistente (los grupos como sujetos de transformación y protagonismo) de la experiencia callejera, pero todos, de algún modo, enfatizan la dimensión del reconocimiento y del empoderamiento. La actitud violenta y criminal, criterio definitorio de banda en el enfoque patológico, pasa a ser un recurso a utilizar y una contingencia que los grupos comparten con otras agencias sociales ${ }^{11}$. Retomando la lección de Delgado, la violencia no es considerada como una cualidad de las prácticas, sino más bien como «un atributo que alguien — considerado legitimado - aplica desde afuera para denunciar alguna cosa perversa que tiene que ser controlada, denunciada, o neutralizada» (Delgado, 1999: 7).

\section{La acción etnográfica: entre autonomía y control político}

Como en el caso de otros objetos científicos, los académicos recuperan el discurso de las bandas una vez que está asentado en la opinión pública como evento problema. Esta recuperación se encadena con otras formas de enunciación, clasificación e intervención impulsadas por distintas agencias. A menudo, de las narraciones instituidas y de las visiones hegemónicas también derivan, o se sustentan, las formas de intervención pensadas como correctas y reconocidas para solucionar el objeto problema.

En los dos contextos analizados — Barcelona y Madrid—, los académicos (en particular antropólogos, sociólogos y psicólogos sociales) fueron parte activa en la construcción de un discurso y en las intervenciones en la escena pandillera. Su posicionamiento se articula entre el método, la epistemología de investigaciónacción y una teoría crítica de signo construccionista sobre las bandas, lo cual configura un modelo de trabajo que rompe con el paradigma de la neutralidad y que pretende implicar figuras distintas en un diálogo compartido: diseñadores de políticas, investigadores, trabajadores sociales y miembros de los grupos juveniles. Este modelo plantea un proceso de investigación que involucre a los sujetos, que se sitúe muy cerca de ellos, que tenga en cuenta sus propuestas de acción y que pueda, de esta forma, guiar el trabajo social y la decisión política. Una práctica de la etnografía como activismo (Brotherton, 2010) que se enfrenta a menudo con las relaciones de poder en el campo de las intervenciones.

Asumimos esta clase de académicos como actores y autores en el campo, portadores de un capital específico y legitimado (el capital cultural, la producción de saber científico) que, en virtud del habitus profesional adoptado (la investigación que apunta a la transformación), están orientados a acumular relaciones significativas con miembros y líderes de los grupos callejeros, lo que, en términos de Bourdieu, se define como «capital social».

11. Si las bandas son violentas por definición, muy raramente es considerada así la policía cuando ejerce violencia extralegal sobre sus miembros, de modo que, cuando las violencias ejercidas desde el Estado llegan a la luz, se habla, por supuesto, de casos individuales y no de un grupo violento en sí mismo. En mis investigaciones realizadas en Italia y España, el abuso policial sobre estos sujetos aparece de manera intensa y recurrente, por ello, podríamos decir que es un punto clave de las relaciones entre juventud callejera e instituciones. 
Tanto en Barcelona como en Madrid, los dos grupos de investigación implicados se situaron como sujetos de producción del discurso sobre el fenómeno, un discurso que se sustentaba en una práctica etnográfica, es decir, de producción de conocimiento mediante producción de relaciones y confianza dentro de la escena pandillera. En ciertos momentos, estos investigadores se transformaron también en fuentes legitimadas, expertos convocados por los medios de comunicación para hablar sobre, y a veces por, los grupos callejeros. Sin embargo, esta articulación entre capital cultural y capital social, en el marco de una investigación-acción que anunciaba la búsqueda de objetivos propios, gozaba de distintos niveles de legitimidad política, la que en última instancia define lo que puede ser una intervención viable, y financiable, sobre el fenómeno.

En el caso de Barcelona, los académicos entran en el campo en 2005 a raíz de un encargo institucional del Ayuntamiento, en el que se pide un informe científico y un diagnóstico sobre la juventud latina en general, para fundamentar las políticas y para intentar salir del modelo secta ${ }^{12}$ que hasta aquel punto articulaba las intervenciones, es decir, un modelo de tratamiento de los jóvenes con el fin de favorecer su salida de las bandas, consideradas como adicción psicológica. Según este modelo, las bandas eran sectas, y las técnicas para luchar contra ellas eran desprogramar, aislar y reprogramar. Así nos habla Carles Feixa, el director de aquella investigación:

[el Ayuntamiento] quería planificar sus políticas no en base a mitos, sino a realidades. Y, en segundo lugar, tenía interés en contactar con ellos [los pandilleros] y no se atrevía o no sabía cómo hacerlo, y pensaron que a través de una investigación eso se podía conseguir.

Gracias a las relaciones abiertas por la investigación entre académicos y líderes de los grupos en aquel entonces hegemónicos — Latin Kings y Netas-, se origina, según este relato, una idea de intervención alternativa: la transformación de los grupos en asociaciones formales. Vemos como el director de la investigación reconstruye el surgimiento de un enfoque para la gestión pública de las bandas:

Yo les dije [a los lideres de los Latin Kings] que me gustaría hacer una investigación e incorporar su voz a ese proceso y que estaba dispuesto a ponerlos en contacto con el Ayuntamiento si ellos lo deseaban. Ellos en seguida me preguntaron por el tema de la legalización: «Es que nos gustaría podernos legalizar. ¿Crees que sería factible?». [...] Esos días fueron de mucha tensión

12. Este tipo de intervención, en realidad, nunca dejó de funcionar. En las entrevistas realizadas en 2012 a profesionales de los servicios sociales, siguen apareciendo casos de jóvenes de bandas derivados al tratamiento por parte de empresas antisectas (entre otras, se destaca AIS - Atención e Investigación en Socioadicciones, por su trayectoria dentro del sistema catalán de salud; www.ais-info.org). La misma empresa proporciona, entre sus servicios, talleres de ex miembros y actividades de prevención antibandas en las escuelas de muchos ayuntamientos de Cataluña. 
para mí, porque tenía que hacer un informe de investigación, pero, al mismo tiempo, había la posibilidad de hacer una intervención muy interesante. Opté por centrarme en la gestión del conflicto y dejar la investigación en un segundo término. Desde junio hasta prácticamente septiembre, estuve dedicando muchas horas a ponerlos en contacto con ciertos actores.

En cierto modo, vemos aquí aparecer una tensión entre un grupo de investigación que se piensa a sí mismo como autor en el campo y un encargo de investigación que no prevé una dimensión aplicada, sino que solo pretende realizar un diagnóstico alternativo a los existentes. Por la lógica de la etnografía, quienes iban acumulando el capital social con los grupos eran los investigadores contratados, cuyo objetivo más general en el campo era impulsar el reconocimiento de las bandas en su calidad de culturas juveniles y el empoderamiento de los miembros; pero solo el capital político permitía canalizar este nuevo discurso, así como las relaciones acumuladas, en el marco de un modelo de intervención legítimo. La investigación-acción nace en Barcelona de una práctica de hecho protagonizada por los académicos, más que de las expectativas formales vinculadas al encargo. Finalmente, el trabajo académico cristaliza en un informe de 2005 que sienta las bases de una nueva política sobre el fenómeno y produce un cambio radical de narración frente al discurso barbárico vehiculado hasta aquel entonces por los medios de comunicación (Feixa et al., 2006).

Los conflictos que empiezan a visibilizarse entre académicos e instituciones a la hora de transformar un diagnóstico en líneas de intervención tienen que ver con el tema de la autonomía de la investigación, de la orientación del proceso social y político en marcha y de la valoración del papel de los grupos en el contexto abierto por la intervención. Lo que desde afuera se veía en términos de complicidad entre actores — el modelo Barcelona — estaba, en realidad, marcado por múltiples fracturas, una de las cuales implicaba los espacios de aterrizaje de los grupos una vez salidos de la clandestinidad en la calle. Más allá de la sustancia del conflicto - espacio laico o espacio religioso de acogida — se medía allí, en su carácter de pretexto, un efecto de poder: ¿quién dirige este proceso? ¿Quién lo paga o quién, gracias a un trabajo acumulado de proximidad, tiene la confianza de los grupos callejeros? ${ }^{13}$.

Si, desde la investigación, se enfatizaba la necesidad de la implicación y de la producción de lazos de confianza, desde las instituciones públicas que lideraban el proceso, se asumía, inversamente, la distancia como condición de una buena gestión y de un conocimiento fiable de los grupos.

[...] me sorprendió ver a los investigadores, y otros participantes «oficiales» en una universal a las que nos invitaron los Latin Kings, dando alaridos «Amor de rey». Me pareció una teatralización que estaba fuera de lugar. Allí fui consciente del riesgo y la importancia de la separación entre el objeto de análisis y

13. Un funcionario entrevistado en el Ayuntamiento de Barcelona me recuerda un principio básico de las relaciones entre política e investigación: "Quien paga, manda». Manda sobre lo que se investiga y sobre el uso y la aplicación del saber producido. 
la intervención, tanto del investigador como, en mi caso, del gestor público. Es aquello de involucrarte tanto en una historia que, al final, te impide ver con una cierta distancia el fenómeno sobre el que has de intervenir. (Funcionario del Ayuntamiento de Barcelona, Dirección de Prevención)

Lo que estaba sobre la mesa era la dirección misma del proceso en sus objetivos: si los académicos postulaban un reconocimiento de tipo multicultural de los grupos, los funcionarios y los políticos del Ayuntamiento buscaban una asimilación y una invisibilización de los mismos, es decir, un reconocimiento que ayudara a reducir el daño social en términos de generación de violencias y de estigma y que, poco a poco, hiciera desaparecer a los grupos callejeros objeto del tratamiento. Si la cara pública y mediatizada del proceso se enmarcaba en una narración de signo multicultural, la cara oculta y hegemónica seguía trabajando - por medios no represivos - en el objetivo de la desaparición de los grupos.

El grupo de investigación tenía la visión del grupo como colectivo importante [...] El Ayuntamiento se planteaba una estrategia de transformación de los grupos en la dirección de su desaparición, mientras que, para el equipo investigador, la consolidación de los grupos como organización de la calle era relevante, estaba más en la dinámica de equipo que se transforma en un colectivo o en un proceso político, consideraba que la existencia de un grupo de estas características socialmente tenía un valor. (Funcionario del Ayuntamiento de Barcelona, Dirección de Prevención)

En cierta manera, los políticos querían un conocimiento de tipo positivista que no pusiera en discusión el monopolio institucional de la intervención con los grupos, mientras que los investigadores se colocaban dentro del marco de la investigación-acción, es decir, como sujetos relativamente autónomos en un proceso en marcha que pretendía cambiar la dinámica y la estructura de los grupos. Si el Ayuntamiento quiso normalizarlos, los investigadores redefinieron críticamente este deseo institucional en términos de domesticación, es decir, la conversión de los grupos en sujetos no conflictivos y la elaboración de mecanismos de control suave a través del trabajo social. En este sentido, la descripción del modelo Barcelona por parte de lo que fue entre 2007 y 2009 su principal ejecutor operativo a pie de calle -Fedelatina ${ }^{14}$ — aparece como la espuma pública de unas relaciones muchos más complejas, ya que el papel académico no puede ser reducido a la simple producción de un conocimiento funcional.

Yo creo que el modelo Barcelona es un trabajo colectivo. Todos (la academia, la policia, los educadores, el Ayuntamiento) queríamos que la organización (las asociaciones derivadas de las bandas) funcionara, que los chicos abandonasen la violencia, y dar a conocer ese fenómeno que nadie conocía. (Responsable del proyecto Jóvenes, Fedelatina)

14. Una federación de distintas asociaciones de migrantes latinoamericanos en Cataluña. 
La divergencia sobre las reglas del juego — subalternidad o autonomía de la investigación en relación con la gestión y la política - origina la expulsión del actor académico de un proceso que solo había empezado, y todavía no había llegado a su auge, con la formalización de los estatutos asociativos de Latin Kings y N Netas entre julio de 2006 y marzo de $2007^{15}$. No es casualidad que muchos conflictos también girasen alrededor de la visualización, es decir, quién representaba públicamente el proceso en su exposición mediática, que, por cierto, en una época fue muy intensa (Queirolo Palmas, 2013). Pero, como ya nos había enseñado Bourdieu, los intelectuales a menudo somos el segmento dominado entre las clases dominantes y, en este caso, para retomar el poder en el campo por parte de los actores políticos, solo fue necesario no renovar la financiación sobre la que se sustentaba el trabajo académico.

Antes de la legalización de los Latin, antes del verano de 2006, el Ayuntamiento toma el mando. Me llaman para hacer una reunión con los Latin Kings. [...] Vino una asistente social y un educador y el Ayuntamiento nos dijo casi literalmente: «Bueno, ya no os queremos a vosotros. Ahora esto pasa a ellos y les tenéis que traspasar la confianza, los contactos, los datos. Ahora ya la investigación se ha acabado. Podéis seguir, pero solo académicamente y ahora el tema pasa a los servicios sociales». Yo les pasé formalmente el contacto y nada más. La confianza no se puede transmitir, se tiene que ganar. La idea del Ayuntamiento era que se convirtieran en un grupo naturalizado como tantos otros, un grupo de moda, que no dieran muchos problemas. [...] Nosotros, en parte, desarrollamos la tarea de intelectual orgánico, es decir, de expresar los deseos de la banda en términos comprensibles para la sociedad. Ese papel, que hasta ese momento había cumplido nuestro equipo, empieza a cumplirlo una asociación financiada por el Ayuntamiento. (Entrevista con Carles Feixa)

Con este ritual, vivido como un acto simbólico y material de expulsión, se acaba el rol de asesor del Príncipe que, desde 2005 hasta el verano de 2006, tuvo el equipo académico en Barcelona. Después, el grupo de investigación

15. Los Latin Kings, en julio de 2006, conforman la Organización Cultural de Reyes y Reinas Latinos de Cataluña. En marzo de 2007, nace la Asociación Sociocultural, Deportiva y Musical de Ñetas. En el primer caso, es interesante la construcción de un referencial catalán en el nombre oficial como proceso de mimetismo en el marco de un modelo nacional de asimilación. En el segundo, se evacúa la referencia al tema de la lucha por los derechos de los presos, constituyente de la historia de los Ñetas. Según los relatos que hemos colectado entre los miembros y dirigentes de los grupos convertidos, se ha tratado de actos de domesticación promovidos, y exigidos, por las instituciones. Hay que añadir que, en Barcelona, los Netas siempre se mantuvieron menos disponibles en el proceso de domesticación institucional: no quisieron participar en la investigación, no formaron parte de las actividades promovidas por Fedelatina. También en Madrid el trabajo de investigación-acción se concentró sólo en los Latin Kings. Dejarse investigar por sociólogos y antropólogos entra en cortocircuito con el culto del secretismo que muchos de estos grupos mantienen, como forma de autodefensa en relación con los aparatos represivos del Estado. Sobre la importancia de escribir su propia historia a través del respaldo de los investigadores, véase la entrevista a King Tone — ex líder de los Latin Kings de Nueva York-, realizada en el marco del proyecto del documental Buscando respeto. 
no llegará a acceder a encargos ad hoc por parte de las instituciones locales y seguirá trabajando de forma autónoma, sobre todo a través de la financiación de proyectos (europeos, locales y nacionales) por convocatoria, protagonizando un trabajo empírico en estrecho contacto con el liderazgo de los Latin Kings. El trabajo colectivo se interrumpirá a partir de 2008. Las pocas investigaciones que se realizaron sucesivamente no fueron por encargo directo - para fomentar la evaluación y el asesoramiento de las políticas de juventud-, sino por convocatorias públicas en el marco de programas sobre migraciones, juventud y uso del espacio urbano.

En el caso de Madrid, la autonomía científica fue garantizada por el hecho de que ningún respaldo político resultó posible y la investigación no nació de un encargo oficial. Si, en Barcelona, los académicos sentían, hasta cierto momento, que formaban parte de un campo - conformado por distintos actores - en el que, sin embargo, el liderazgo del proceso había sido tomado (entre 2005 y 2007) por las instituciones locales y el lado social de las políticas (la mano izquierda del Estado, en términos de Bourdieu), y en ello peleaban para afirmar una cierta autonomía e impulsar sus objetivos, en Madrid, los mismos sujetos se pensaban a sí mismos como figurantes, dentro de un campo secuestrado desde arriba por la mano derecha del Estado. Allí, la estrategia de los actores dominantes fue la ilegalización y la persecución penal de los grupos.

Es en este marco donde se desarrolla, desde 2007 hasta 2009, un proceso de investigación-acción con el grupo de los Latin Kings, cuyos objetivos declarados fueron (Scandroglio y López, 2010) los siguientes:

1) Prevenir la realización de enfrentamientos violentos por parte del grupo.

2) Incrementar la capacidad del grupo para actuar como recurso autónomo y efectivo de apoyo e integración social para sus miembros.

3) Convertir el grupo en un agente social reconocido, legítimo y conectado con las redes sociales e institucionales de su entorno, lo que implica la constitución en asociación y la transformación del estigma en los medios.

Estas acciones, realizadas desde un enfoque de psicología social y que incorporaban un intenso trabajo social, de hecho iban en dirección contraria a lo que los demás actores en el campo realizaban, impulsaban y deseaban: hacer desaparecer a los grupos penal y socialmente, deteniendo y deportando (la mano derecha), desvinculando y reeducando (la mano izquierda). Los académicos fueron, al mismo tiempo, el brazo y la mente de una intervención social en un medio muy hostil que, a diferencia de la actuación de las instituciones en Barcelona, no apoyó con financiación, ni dio cobertura política o simbólica a un proceso de transformación de las bandas. La intervención académica en Madrid se interrumpió en 2009, ya que la imposibilidad de ofrecer recursos — tanto de tipo material (formativo-laboral) como de tipo simbólico (reversión de la imagen social barbárica) — a un grupo estigmatizado por las instituciones públicas y el mantenimiento de la presión policial debilitaron y, finalmente, hicieron caer el liderazgo de los Latin Kings que había promovido la transformación interna. 
En primer lugar, nosotros somos incómodos como personas que no colaboran especialmente en ese objetivo, y planteamos una visión de la intervención que es completamente contradictoria respecto a lo que ellos, las fuerzas de seguridad y los políticos, plantean. Entonces, ahí, esa relación es muy conflictiva y se rechaza en términos de argumentos, de que nosotros no somos neutrales, que estamos distorsionando la información, que no vemos la perspectiva real del grupo, cuando en algunas ocasiones realmente nadie tiene las horas de presencia en el grupo, de contacto, así como hemos tenido nosotros. Respecto al colectivo de educadores, siempre nos han mirado con sorpresa, porque les ha parecido una situación fascinante que nosotros tuviésemos acceso directo y continuado con el grupo. Las entidades asociativas no han sido capaces de aproximarse a la perspectiva, porque era completamente contraria a lo que se proponía desde el nivel político, y, aparte, suponía un cierto riesgo, es decir, actuar desde esa perspectiva supone el riesgo que políticamente se suspenda el apoyo y la financiación, porque no es lo que se está marcando como prioridad. (Entrevista con Barbara Scandroglio y Jorge López)

Los actores académicos en Madrid apuntaban, en sus propios términos, a negociar el control social sobre los grupos, es decir, viabilizar un control suave e incluyente que pudiese ir de la mano, en caso de necesidad, de un control policial. Por lo que peleaban era por su inclusión en la coalición dominante en el campo de las intervenciones. Sin embargo, estos académicos, por el habitus transgresivo que desarrollaron, fueron visualizados como sujetos no legítimos, precisamente a partir de un cuestionamiento de su cientificidad, lo que significa que no pudieron ser reconocidos como fuentes y expertos en la producción del discurso hegemónico. Vemos como los actores policiales y de justicia de menores en Madrid, encontrados a lo largo del trabajo de campo, se refieren y categorizan a los académicos:

C. es un jefe de un cuerpo de seguridad y se dedica al estudio y a la intervención sobre bandas: "Nosotros los llamamos grupos juveniles organizados y violentos, pero hay que decir que Netas y Latin Kings tienen solo un simulacro de organización. Y ahora están en auge grupos donde hay más menores, la violencia es más pasional y el funcionamiento, más asembleario. ¿Qué son las bandas? Nosotros utilizamos la definición de Eurogang». Eurogang es el actor intelectual de esta industria, como me dicen los dos académicos - Barbara Scandroglio y Jorge López- que intentaron replicar y aplicar el estilo de Barcelona en Madrid. Los actores institucionales de la mano derecha del Estado entrevistados me hablan de ellos dos como académicos no verdaderos, mientras que se legitiman intelectualmente a través de Eurogang. Cuando yo los cito, los actores que encuentro en lo policial y en justicia de menores me alertan: «Ellos están comprometidos, implicados, no son distantes. Tienes que hablar tú con $\mathrm{X}$ e Y, los que trabajaron para nosotros, ellos sí son científicos». En fin, entiendo que hay verdaderos y falsos académicos. (Diario de campo, mayo de 2012)

La distancia en relación con el objeto del tratamiento, de la intervención y del pensamiento es, por ende, constituyente de este habitus positivista a través 
del cual es pensada la ciencia. La empatía no es permitida. Son etiquetados como no verdaderos aquellos académicos que buscan alguna clase de organicidad con los sujetos subalternos, sin embargo, es invisibilizada la relación de proximidad y complicidad de los presuntos verdaderos académicos con sus fuentes de financiación y encargos dentro de una creciente industria de las bandas.

\section{Conclusiones: intelectuales orgánicos y académicos embedded}

Si, en Barcelona, el Príncipe deja en la calle a sus asesores y después decide no recurrir a sus obras, es también porque estos iban desempeñando - o pretendían hacerlo-, con el consenso del grupo más grande y mediático — los Latin Kings-, aquel papel que Gramsci, refiriéndose a la relación con el partido comunista en su calidad de partido de la clase obrera, había nombrado con la expresión de intelectuales orgánicos: los investigadores son coronados por el liderazgo de los Latin Kings como voz del grupo y articuladores de un discurso sobre sus necesidades frente a las instituciones y de una opinión pública asustada por la asociación permanente entre crimen, juventud y migración.

En la concepción clásica gramsciana, cada grupo social de relieve construye sus intelectuales orgánicos, ya que la lucha por el dominio siempre se sustenta sobre la imposición de una visión del mundo, sobre una hegemonía cultural. En este sentido, los intelectuales no son una capa independiente de los vínculos sociales y su expresividad conecta la relación entre clase y partido, y, al mismo tiempo, la constituye y la performa. El partido se vuelve, así, a través de sus intelectuales orgánicos y de su trabajo de imposición de la hegemonía, un intelectual colectivo ${ }^{16}$.

¿Qué intelectuales orgánicos son los que sitúan su habitus en la representación, el acompañamiento o la producción de discursos para la escena pandillera, siendo que esta articulación es totalmente distinta a la relación entre clase, partido y estado a la cual se refería el pensamiento gramsciano? ¿Cuál es la clase y cuál es el partido en este escenario?

Nos pueden ayudar a contestar a estas preguntas, por un lado, las reflexiones de Spivak (2011) y del enfoque poscolonial en sus interrogaciones sobre la posibilidad de los subalternos de hablar y, por otro, los aportes de Cerbino y Rodríguez (2010) sobre la figura de los investigadores frente a la escena pandillera.

La persistencia y reproducción de los grupos callejeros en las sociedades posmigratorias contemporáneas son el espejo de la crisis y un indicador evidente del colapso de la integración auspiciada para los hijos de las migraciones. La escena

16. Podríamos contrastar esta concepción de la organicidad de los intelectuales a la clase y al partido en la construcción de la hegemonía con un enfoque que, recuperando la categoría de general intellect en Marx, identifica en la multitud (Hardt y Negri, 2004) un sujeto cuya representabilidad en la forma de partido se vuelve difícil y pone en tensión la búsqueda gramsciana de una articulación orgánica. Siguiendo las sugerencias de Hallsworth (2011), podríamos agregar que las representaciones sobre bandas son arbóreas y piramidales, mientras que los espacios de constitución y sociabilidad desde las bandas son, a menudo, rizomáticas y fluidas; lo que, una vez más, pone en tensión el papel del intelectual. 
pandillera nos habla, siguiendo la lectura poscolonial, de la agencia de los subalternos, figuras donde se reflejan relaciones de raza, género y clase, por supuesto fuera de cualquier mitología de homogeneidad y de unidad de las clases dominadas. En este sentido, la juventud proletaria y posmigratoria es la clase, y las bandas, sus múltiples partidos. Estas figuras y agencias subalternas, como ya hemos visto, se revelan — son capturadas por la mirada instituida - a través de tropos y metaforizaciones barbáricas y patológicas. Spivak añade que el subalterno solo puede ser representado, y lo es gracias a discursos y archivos coloniales; sujetos mudos cuya resistencia no transita en la toma directa de la palabra, sino oblicuamente, a través del éxodo, el rechazo, la evasión y otras prácticas de aislamiento o de construcción de espacios paralelos. Las bandas constituyen y performan estos espacios paralelos y producen un lenguaje y un sistema de estatus que circulan por allí sin ser escuchados ni reconocidos en la esfera de la política y del Estado.

La investigación-acción se sitúa como puente entre las bandas - los partidos de la escena pandillera-y las instituciones estatales. Hacer de la ciencia un trabajo de intelectual orgánico en este contexto significa "producir una escritura del proceso que permite dar lugar a una reflexión y a una teorización sostenidas hacia objetivos diferentes de los objetivos políticos» (Cerbino y Rodríguez, 2008: 73), lo que supone la posibilidad de crear un conflicto entre este habitus académico y la política, y que, sin embargo, tampoco impide la posibilidad de que surja un conflicto con los liderazgos en la escena pandillera, por las tentaciones siempre presentes de una representación exótica y colonial por parte de los académicos.

Por otro lado, cabe la hipótesis de que el investigador se convierta en una especie de otredad [...] para sujetos cuyo universo de alteridad ha estado marcado por el signo de la exclusión, y para los cuales las únicas otredades posibles han sido las de enemigos que hay que aniquilar (los miembros de agrupaciones rivales) o las miradas estigmatizadoras y discriminatorias de la opinión pública. [...] La apuesta del investigador-interventor va de algún modo en la dirección de representar la condición de producción de «efectos de sujeto» en las personas involucradas en el proceso de intervención; entendemos con ello el aparecimiento de nuevos interrogantes, nuevas dudas, nuevos cuestionamientos que antes eran impensables. (Cerbino y Rodríguez, 2008: 73)

El papel del investigador como interventor, de la investigación-acción como posibilidad de constitución de las condiciones de una escritura de los subalternos que hable de frente en el espacio público de los dominantes es, por cierto, frágil y problemático. Ser orgánico a la escena pandillera para estos intelectuales significa la restitución de una voz no escuchada y de una escritura no leída, de sujetos que sí hablan y escriben, pero que lo hacen de modo ventrílocuo ${ }^{17}$ ante los ojos de las clases dominantes.

17. Es suficiente navegar en el archivo visual y musical de YouTube o moverse en las redes sociales especializadas, para darse cuenta de la inmensa capacidad de autorrepresentación de estos sujetos subalternos, lo que también cuestiona el posicionamiento de Spivak, puesto que el subalterno precisamente deja de serlo cuando habla. 
Es precisamente esta condición de los académicos como intelectuales orgánicos la que llega a ser negada por las instituciones que, en Cataluña, no distintamente de otros lugares, apuntan a la normalización y la desaparición de los grupos, y no a su consolidación en el marco de una política de signo multicultural. Por otro lado, la investigación, al posicionarse como autónoma frente a las instituciones - como en el caso de Madrid - vivió otro cortocircuito, es decir, perdió su utilidad frente a los grupos callejeros y no pudo funcionar, a falta de un capital político, como canalizadora de un acceso a los recursos.

Por supuesto, la intervención etnográfica es solo una parte minoritaria del campo académico. La hegemonía material (los recursos de financiación de la investigación) y simbólica (la circulación y producción de un discurso) está del lado de aquellos académicos embedded que conforman la que Hallsworth (2011), entre otros, ha llamado gang industry, una industria que tiene que producir un monstruo para recibir financiaciones. En este sentido, el objeto bandas, su representación por parte de los actores institucionales y mediáticos, es el producto de esta industria, en la cual participan, como intelectuales orgánicos (articuladores de discursos y receptores de financiaciones), segmentos importantes del campo académico que experimentan allí una complicidad, interesada e interesante, con el discurso policial. Los académicos embedded son ellos mismos intelectuales orgánicos, asesores de otros partidos que gozan de un mayor capital simbólico y político.

En el mes de mayo de 2012, asisto a una gran conferencia de la red Eurogang junto a los directores de los dos equipos que han protagonizado la investigación en Madrid y Barcelona. Estas son mis notas de campo:

Una discípula importante clausura una sesión de la conferencia y, después de haber construido una extraña tipología de bandas, hará ver una foto de su oficina: ella sepultada por papeles. Nos damos cuenta de que estos académicos viven en un mundo de papers, citaciones, impact factor, cada uno en su parroquia y en su mercado más o menos prometedor - y lo de las gangs lo es- $y$ de colegas que hacen lo mismo y los confirman en este habitus de trabajo. Me acuerdo de una frase de Howard Becker que critica esta clase de académicos como inútiles ${ }^{18} \mathrm{y}$ al final entiendo lo importante [...] esta gente, a diferencia de

18. Escuchamos a Becker (2007: 27-28), utilizando como inspiración un artículo de Molotch (1994): «Es decir que, si uno quiere escribir acerca de la sociedad, antes tendrá que conocerla de primera mano y, particularmente, tendrá que conocer lugares que la gente respetable no frecuenta: El salón donde a las bailarinas les pagan para bailar con los clientes, los complejos de viviendas sociales, las marchas de protesta, la pandilla de jóvenes y los lugares oscuros que la mayoría de nosotros solo conoce como indicios acechantes de lo posible. [...] En la mayoría de los casos — añade Molotch - los sociólogos no conocen otro mundo que el de su ronda diaria académica y familiar; no recorren las bolsas de negociación de bienes tangibles ni frecuentan iglesias alternativas ni clubes de golf exclusivos. Las reuniones de comité, los deberes de la enseñanza, la revisión por pares y la escritura de ensayos como éste son su única preocupación, y dejan poco o ningún espacio para andar por el mundo. En una primera versión de su diagnóstico, Molotch define al sociólogo como alguien que gasta cien mil dólares en el estudio de la prostitución para descubrir lo que cualquier taxista podría haberle dicho» (traducción al castellano por parte del autor). Este habitus es precisamente lo que define a muchos académicos, entre 
los policías, nunca ha visto ni se ha relacionado con un pandillero en su vida. (Diario de campo, mayo de 2012)

Las tensiones entre el papel desempeñado por los académicos y sus destinos en cuanto actores y autores en los dos contextos, y además dentro del mismo contexto en el caso de Cataluña, son reveladoras de las dificultades que se generan a la hora de reimaginar las ciencias sociales como herramienta de transformación. Lo que el equipo en Madrid lamenta como una de las causas que determinaron un fracaso de la intervención — la falta de apoyo políticoes exactamente, por contra (el liderazgo por parte del Ayuntamiento de un proceso de normalización de los grupos), lo que contribuyó en Barcelona a expulsar a los académicos de la coalición dominante en el campo de las intervenciones sobre bandas. Después de 2007, Barcelona se iguala a Madrid y la investigación-acción muere por falta de capital político.

En los dos casos, los académicos monopolizaban en parte el capital social, las relaciones de confianza con ciertos grupos callejeros, lo cual convirtió este capital social en un nuevo y original capital cultural (conocimiento y notoriedad en la academia y en la opinión pública), hasta aquel tiempo indisponible, estando la percepción de los grupos fundamentada sobre mitos y leyendas dentro de un marco patológico. En los dos casos, los académicos - en virtud de los capitales acumulados y con el consenso de los grupos con que más proximidad tenían - también trataban de operar como intelectuales orgánicos.

En Barcelona, esta dinámica entre capital social y cultural fue, por un lado, valorada por las instituciones y, por otro, expropiada, lo cual afirmó la autonomía del político frente a la autonomía de la ciencia en la construcción de las intervenciones, en sus objetivos y metodologías. En Madrid, la relación que la investigación-acción construyó entre capital social y cultural fue marginada, deslegitimada y, finalmente, expulsada del campo para poder afirmar la autonomía del político en la utilización coyuntural de estos grupos como sujetos barbáricos y chivos expiatorios ideales.

En los dos contextos, en fin, los académicos que protagonizaron la investigación-acción no pudieron ser orgánicos ni para los diseñadores de políticas, ni tampoco para los grupos que, en cierto modo, los habían coronado o habían hecho una apuesta sobre la utilidad de este papel.

Hoy en día, la estrategia de la ilegalización y del espectáculo de los golpes policiales es hegemónica, tanto en Madrid como en Barcelona. A lo largo de la investigación etnográfica, se dedicó mucho tiempo a observar el trabajo cotidiano de los cuerpos policiales. Escuchamos aquí los relatos de unos policías inconformes que fueron miembros de un grupo especializado en bandas:

otros, los investigadores de bandas, que, enmarcándose dentro del habitus positivista de la ciencia, nunca se encontraron directamente con los objetos de sus investigaciones, sino a través del formato paper. Los policías, al revés, por su calidad de burócratas de calle, tienen una imagen mucho más próxima y densa de los sujetos sobre los cuales intervienen. 
Agente 1: Policialmente, no se puede trabajar como cacería..., y tomar las calles.

Agente 2: Los chicos están en paro. Es normal que trabajen un poco en la droga. Sí, en frente de las discotecas, cada grupo tiene su tiendita. No toman ni un cubata adentro porque trabajan afuera, pero si me pides si tienen negocios de verdad, te digo que los negocios son otros. [Los jefes] quieren hacer alguna operación espectacular donde arrestan a los líderes y dicen que acabaron con las pandillas. Pero, como tú sabes, esto no lo terminas con estas operaciones.

Agente 3: Nos dictaron estas líneas en la última reunión: "A por ellos, basta de buenismo. Detenciones, detenciones. Nada de prevención, represión. Hay un nuevo protocolo».

Agente 4: Cuando van a las detenciones, dicen: «iVamos a los putos negros!». Y tú oyes solo lo que dicen en público, no ves el interior. Se montan el uno con el otro... Tú escuchas comentarios inescuchables. En dos meses, volvimos a la policía franquista. Es un tema político.

En medio de la crisis, queda la mano derecha del Estado — con sus dispositivos policial, penal y carcelario_ - como actor hegemónico para vigilar, castigar, encarcelar y deportar a este segmento de la juventud migrante y proletaria.

\section{Referencias bibliográficas}

Aparicio, Rosa; Tornos, Andrés; Cabala, Sileny (2009). Aproximación al estudio de las bandas latinas de Madrid. Madrid: Ministerio de Trabajo e Inmigración.

BeCKer, Howard (2007). I trucchi del mestiere: Come far ricerca sociale. Bolonia: Il Mulino.

Bourdieu, Pierre (1998). Acts of Resistance: against the Tyranny of the Market, New York: The New Press.

Bourdieu, Pierre (2012). Sur l'État: Cours au Collège de France, 1989-1992. París: Seuil.

Brotherton, David (2010). "Oltre la riproduzione sociale: Reintrodurre la resistenza nella teoria sulle bande». En: Queirolo Palmas, Luca (ed.). Atlántico latino: Gang giovanili e culture transnazionali. Roma: Carocci.

Brotherton, David; Barrios, Luis (2004). The Almighty Latin King and Queen Nation: Street Politics and the Transformation of a New York City Gang. Nueva York: Columbia University Press.

Cachón, Luis (2007). «El Plan Estratégico de Ciudadanía e Integración 2007-2010 y la Juventud Inmigrante». En: López Sala, Ana María; Cachón, Lorenzo (coords.). Juventud e inmigración: Desafios para la participación y para la integración. Canarias: Dirección General de Juventud de la Consejería de Empleo y Asuntos Sociales del Gobierno de Canarias.

Canelles, Noemi (2008). "Jóvenes latinos en Barcelona: La construcción social de las bandas». En: Barrios, Luis; Cerbino, Mauro (eds.). Otras naciones: Jóvenes, transnacionalismo, exclusión. Quito: FLACSO.

Cerbino, Mauro (2011). Más allá de las pandillas: Violencias, juventudes y resistencias en el mundo globalizado, vol. 1 y 2. Quito: FLACSO.

Cerbino, Mauro; Rodríguez, Ana (2008). «La nación imaginada de los Latin Kings: Mimetismo, colonialidad y transnacionalismo». En: Barrios, Luis; Cerbino, Mauro (eds.). Otras naciones: Jóvenes, transnacionalismo, exclusión. Quito: FLACSO. 
- (2010). «La nación Latin King: Desafío para repensar lo nacional». Nómadas, 32, 117-133.

Cloward, Richard A.; Ohlin, Lloyd E. (1960). Delinquency and Opportunity: A Theory of Delinquent Gangs. Nueva York: The Free Press.

Cohen, Albert K. (1955). Delinquent Boys: The Culture of the Gang. Nueva York: The Free Press.

Conquergood, Dwight (1997). «Street Literacy». En: Flood, James; Heat, Shirley B.; Lapp, Diane (eds.). Handbook of Research on Teaching Literacy through the Communicative and Visual arts. Nueva York: Simon and Shuster MacMillan.

Cuesta, Armanda; Cuesta, Mery; Fernández Porta, Eloy; Méndez, Sabino (2009). Quinqui del 80: Cine, prensa y calle. Barcelona: CCCB.

Delgado, Manuel (1999). "La violència com a recurs i com a discurs». Aportacions, 7. Barcelona: Generalitat de Catalunya. Secretaria General de la Joventut.

Feixa, Carles (1998). De jóvenes, bandas y tribus. Barcelona: Ariel.

Feixa, Carles; Cerbino, Mauro; Recio, Carolina; Porzio, Laura; Canelles, Noemi (2006). "De las "bandas" a las "organizaciones juveniles"». En: FerxA, Carles; Porzio, Laura; Recio, Carolina (coords.). Jóvenes "latinos» en Barcelona: Espacio público y cultura urbana. Barcelona: Anthropos.

Feixa, Carles; Scandroglio, Barbara; López Martinez, Jorge S.; Ferrándiz, Francisco (2011). «Organización cultural o asociación ilícita?: Reyes y Reinas Latinas entre Madrid y Barcelona». Papers, 96 (1), 145-163.

García Borrego, Iñaki (2003). «Los hijos de inmigrantes extranjeros como objeto de estudio de la sociología». Andulí: Revista Andaluza de Ciencias Sociales, 3, 49-67.

- (2010). "Jóvenes de origen migrante: Desigualdades y discriminaciones». Revista de Estudios de Juventud, 89, 125-142.

Giliberti, Luca (2010). «Les organitzacions juvenils de carrer». En: Porzio, Laura; Giliberti, Luca; Hakim, Nadia; Rodríguez, Alexis; Muller, Torben (coords.). Escenaris urbans, adscripció identitària i estils: joves i espai públic: La mirada des dels municipis. Informe de recerca. Barcelona: Diputació de Barcelona. Àrea d'Igualtat i Ciutadania.

González-Anleo Sánchez, Juan M.; López Ruiz, José A.; Valls Iparraguirre, Maite; Ayuso Sánchez, Luis; González SAnz, Gonzalo (2010). Jóvenes españoles 2010. Madrid: Ediciones SM-FSM.

Hallsworth, Simon (2011). "Anatomizing Gang Talk». En: Cerbino, Mauro (coord.). Más alla de las pandillas: Violencias, juventudes y resistencias en el mundo globalizado, vol. 1. Quito: FLACSO.

Hardt, Michael; Negri, Antonio (2004). Multitud: Guerra y democracia en la era del Imperio. Buenos Aires: Debate.

Katz, Jack (1988). The Seduction of Crime: Moral and Sensual Attractions in Doing Crime. Nueva York: Basic.

Kazyrytski, Leonid (2008). Consideraciones criminológicas en torno a las bandas callejeras de origen latinoamericano en Cataluña. Tesis doctoral. Girona: Universitat de Girona.

KLeIN, Malcom W. (1971). Street gangs and street workers. Englewood Cliffs, NJ: Prentice-Hall.

Maqueda Abreu, María Luisa (2010). «Aproximación a la violencia juvenil colectiva desde una criminología crítica (bandas, tribus y otros grupos de calle)». Revista de Derecho Penal y Criminología, 4, 271-331. 
Marengo, Gilberto (2012). «Dal daltonismo sportivo all'inclusione strabica: Migrante e capitale guerriero in una palestra di Kickboxing». Mondi Migranti, 3, 181-207.

Martín, María Jesús; Martínez, José Manuel; Rosa, Alberto (2009). «Las bandas juveniles violentas de Madrid: su socialización y aculturación». Revista Panamericana de Salud Publica [en línea], 26 (2), 128-136. <http://dx.doi.org/10.1590/S1020-49892009000800005>

Merton, Robert K. (1980). Teoría y estructura sociales. México: Fondo de Cultura Económica.

Molotch, Harvey L. (1994). "Going Out». Sociological Forum [en línea], 9, 221-239.

Portes, Alejandro; Aparicio, Rosa; Haller, William (2009). La segunda generación en Madrid: Un estudio longitudinal. Informe de investigación. Madrid: Universidad Pontificia de Comillas.

Porzio, Laura; Giliberti, Luca (2009). «Espacio público, conflictos y violencias: El caso etnográfico de las organizaciones juveniles de la calle». En: MárQuez, Iñaki; Fernández, Alberto; Pérez-Sales, Pau (eds.). Violencia y salud mental: Salud mental y violencias institucional, estructural, social y colectiva. Madrid: AEN.

QueIrolo Palmas, Luca (ed.) (2009). Dentro le gang: Giovani, migranti e nuovi spazi pubblici. Verona: Ombre Corte.

- (ed.) (2010). Atlantico Latino: Gang giovanili e culture transnazionali. Roma: Carocci.

- (2012). "The social construction of the youth migration nexus in contemporary Spain: A critical overview». Italian Journal of Sociology of Education, 3, 3-33.

- (2013). «Entre lo barbárico y el olvido: Los medios y la producción de las bandas en la España contemporánea». Quaderns, 29.

Romaní, Oriol; Porzio, Laura; Rodríguez, Alexis; Canelles, Noemí; Giliberti, Luca; MAZA, Gaspar (2009). «De nacions, reialeses i marginacions: L’organització dels reis i reines latinos de Catalunya, un estudi de cas». En: AADD. Recerca $i$ immigració II. Barcelona: Generalitat de Catalunya.

Scandroglio, Barbara (2009). Jóvenes, grupos y violencia. De las tribus urbanas a las bandas latinas. Barcelona: Icaria.

Scandroglio, Barbara; López Jorge, S. (2010). «Investigación-acción participativa con la agrupación de los Latin Kings en Madrid: Potencialidades y límites de una estrategia alternativa al control de los grupos juveniles conflictivos». Revista de Antropología Iberoamericana, 5 (2), 223-255. <http://dx.doi.org/10.11156/aibr.050204>

SpIvaK, Gayatri Chakravorty (2011), ¿Puede hablar un subalterno? Buenos Aires: El Cuento de Plata.

Thrasher, Frederick (1927). The gang: A study of 1313 gangs in Chicago. Chicago: University of Chicago Press, 1963.

Vázquez González, C.; Serrano Tárraga, M. D. (2007). Derecho penal juvenil. Madrid: Dickinson.

Whyte, William F. (1943). Street-Corner Society. Chicago: University of Chicago Press.

Young, Jock (1999). The Exclusive Society: Social Exclusion, Crime and Difference in Late Modernity. Londres: SAGE Publications.

- (2007). The Vertigo of Late Modernity. Londres y Thousand Oaks, CA: Sage Publications. 